\title{
Reactivity to Myelin Antigens in Multiple Sclerosis Peripheral Blood Lymphocytes Respond Predominantly to Myelin Oligodendrocyte Glycoprotein
}

\author{
N. Kerlero de Rosbo, * R. Milo, * M. B. Lees," D. Burger," C. C. A. Bernard, * and A. Ben-Nun" \\ ${ }^{*}$ Neuroimmunology Laboratory, La Trobe University, 3083 Bundoora, Australia; ${ }^{\ddagger}$ Department of Neurology, Assaf Harofeh \\ Medical Center, Zerifin 70300, Israel; \$ Eunice Kennedy Shriver Center, Waltham, Massachusetts 02254; \\ "Division of Immunology and Allergy, University Hospital, Geneva 7211, Switzerland; and \\ "Department of Cell Biology, Weizmann Institute of Science, Rehovot 76100, Israel
}

\begin{abstract}
Although $\mathrm{T}$ cell responses to the quantitatively major myelin proteins, myelin basic protein (MBP) and proteolipid protein (PLP), are likely to be of importance in the course of multiple sclerosis (MS), cell-mediated autoimmune responses to other myelin antigens, in particular quantitatively minor myelin antigens, such as myelin-associated glycoprotein (MAG) and the central nervous system-specific myelin oligodendrocyte glycoprotein (MOG), could also play a prevalent role in disease initiation or progression. Highly purified myelin antigens were used in this study to assess cell-mediated immune response to MOG in MS patients, in the context of the reactivity to other myelin antigens, MBP, PLP, and MAG. The greatest incidence of proliferative response by MS peripheral blood lymphocytes was to MOG, as 12 of 24 patients tested reacted and, of these, 8 reacted to MOG exclusively. In contrast, only 1 control individual of 16 tested reacted positively to MOG. The incidence of responses to MBP, PLP, and MAG did not differ greatly between MS patients and control individuals. A predominant $T$ cell reactivity to MOG in MS suggests an important role for cell-mediated immune response to this antigen in the pathogenesis of MS. (J. Clin. Invest. 1993. 92:2602-2608.) Key words: multiple sclerosis • myelin oligodendrocyte glycoprotein • myelin antigens $\bullet$ cell-mediated immune response $\bullet$ experimental autoimmune encephalomyelitis
\end{abstract}

\section{Introduction}

Multiple sclerosis (MS), ${ }^{1}$ a disease of the human central nervous system (CNS) characterized by perivascular inflammation accompanied by primary demyelination, is believed to result from autoimmune mechanisms leading to myelin destruction (1). Accumulation of activated T cells in early MS lesions, as well as at the periplaque area and in surrounding normal-appearing white matter (2-4), seemingly points to the

Address correspondence to Dr. N. Kerlero de Rosbo, on leave at the Department of Cell Biology, The Weizmann Institute of Science, P.O. Box 26, Rehovot 76100, Israel. 1993.

Received for publication 18 March 1993 and in revised form 6 July

1. Abbreviations used in this paper: CNS, central nervous system; CSF, cerebrospinal fluid; EAE, experimental autoimmune encephalomyelitis; MAG, myelin-associated glycoprotein; MBP, myelin basic protein; MOG, myelin oligodendrocyte glycoprotein; MS, multiple sclerosis; PLP, proteolipid protein; SI, stimulation index.

J. Clin. Invest.

(C) The American Society for Clinical Investigation, Inc.

$0021-9738 / 93 / 12 / 2602 / 07 \quad \$ 2.00$

Volume 92, December 1993, 2602-2608 importance of cell-mediated immune reaction in the pathogenesis of the disease $(1,5)$. In view of the restricted localization of MS lesions to the white matter (6), it is generally accepted that autoimmune-activated T cells in MS CNS recognize components of the myelin sheath. In this context, a purported model for MS, experimental autoimmune encephalomyelitis (EAE), was shown to be a cell-mediated disease that could be caused in susceptible animals by intravenous injection of activated $\mathrm{CD}^{+} \mathrm{T}$ cells specific for the quantitatively major myelin proteins: myelin basic protein (MBP) $(7,8)$ and proteolipid protein (PLP) (9-11). In MS, reactivity to these myelin antigens has been extensively investigated and controversial results indicate that, although specific responses to these antigens are likely to be of importance in the course of the disease, they may not represent the primordial response involved in the pathogenesis (12). It has recently been acknowledged that autoimmune recognition of quantitatively minor myelin autoantigens in MS could also play a prevalent role in disease initiation or progression. Quantitatively minor myelin antigens include myelin-associated glycoprotein (MAG) and the CNS-specific myelin oligodendrocyte glycoprotein (MOG). In contrast to MBP and PLP, which account for most of the protein fraction of CNS myelin ( $\sim 30$ and 50\%, respectively; 13), MAG and MOG constitute only $\sim 1$ and $0.05 \%$ of CNS myelin proteins, respectively $(14,15)$. Because of their low abundance, it is difficult to obtain these antigens in a highly purified form and in sufficient quantities, hence the paucity of reports investigating $T$ cell reactivity to MAG and MOG. Although autoimmune response to MAG may be more important in demyelinating disorders of the peripheral nervous system (16), immune responses to MOG may be highly relevant to CNS demyelination. Thus, despite the fact that only very small amounts of MOG are found in the CNS (17), antibodies to MOG can be detected in the sera of guinea pigs with EAE induced with whole spinal cord homogenate (18). Furthermore, the demyelinating activity of such sera has been attributed to anti-MOG antibodies (19). Corroborative evidence that the presence of anti-MOG antibodies within CNS tissue leads to extensive demyelination has been obtained both in vivo $(20,21)$ and in vitro (22) with a monoclonal anti-MOG antibody (17). If MOG is indeed a target antigen for autoimmune attack, the possible involvement of cell-mediated immune response to MOG is also likely to be an important factor in the pathogenesis of MS.

In this study, the relevance of MOG as a T cell autoantigen was investigated by assessing the reactivity to MOG by PBLs of MS patients and control individuals, in the context of the reactivity to other myelin antigens: MBP, PLP, and MAG.

\section{Methods}

Myelin antigens. Human MBP was purified from neurologically normal human brain according to the procedure of Dunkley and Carnegie 
(23). This highly purified preparation comprises the 18.5- and the 17.3-kD MBP isoforms observed in adult human CNS (Fig. 1 A; 24).

Human MOG was purified from neurologically normal brain white matter or spinal cord according to the procedure of Webb (personal communication; 17) modified as detailed previously (24a). Briefly, membrane proteins were extracted by addition of deoxycholate to human white matter homogenate and MOG was isolated from the solubilized protein fraction by immunoaffinity chromatography on an antiMOG IgG (see below) column. It was eluted, in the absence of detergent, with $50 \mathrm{mM}$ diethylamine, $\mathrm{pH} 11.5$, which was then dialyzed out or removed on a desalting column. Human extracellular derivative of MAG (dMAG) was purified as described previously (25).

PLP was obtained from a washed total lipid extract of bovine white matter (26) and lipid was removed by chromatography on a Sephadex LH60 column (27). It was kept as a chloroform/methanol soluble preparation. On the day PLP was to be used in the proliferation assay, an aliquot of the solvent-soluble preparation was converted to a watersoluble form and dialyzed extensively against large volumes of water for 10-12 h. All preparations contained the two PLP isoforms, PLP and DM-20.

SDS-PAGE and immunoblotting. SDS-PAGE and immunoblotting analyses of the MOG and MBP preparations were carried out on $15 \%$ gels as described previously (24). SDS-PAGE analyses of MAG and PLP were performed on 10 and $12 \%$ gels, respectively (28). Immunoblotting of PLP was performed as described by Yamamura et al. (29) with the following modifications: the blocking solution consisted of PBS containing $2 \%$ nonfat dry milk and the hybridoma supernatant was used undiluted; the second antibody was goat anti-rat IgG conjugated to alkaline phosphatase (Fisher Scientific Co.), and an alkaline phosphatase conjugate substrate kit (Bio-Rad Laboratories, Richmond, CA) was used for detection.

Antibodies. Mouse monoclonal anti-rat MOG antibody (clone $8-18 \mathrm{C} 5 ; 17)$ was purified from ascites fluid by affinity chromatography on a protein G Sepharose 4 Fast Flow column (Cat. no. 17-0618-01; Pharmacia LKB, Uppsala, Sweden) according to the manufacturer's specifications. The cells producing $8-18 \mathrm{C} 5$ antibody were a gift from Dr. M. Webb (Sandoz Institute of Medical Research, London).

Mouse monoclonal anti-human MBP antibody (clone 65 [2-1]; 30) was a gift from Prof. P. R. Carnegie (Murdoch University, Murdoch, Western Australia). It was purified by chromatography on protein G Sepharose 4 Fast Flow.

Mouse monoclonal anti-HNK1 antibody (clone 6-3-19-1) (Cat. no. MON 1010; Sanbio BV-Biological Products, the Netherlands) was used to detect possible contamination of MOG and MBP preparations with MAG, the carbohydrate moiety of which contains the HNK1 epitope $(26,31)$.

Rat monoclonal anti-PLP antibody (clone AB3) was obtained as described (29). Polyclonal anti-PLP antibodies were kind gifts from Prof. W. B. Macklin (UCLA, Los Angeles, CA) and Dr. E. Trifilieff (Centre de Neurochimie du CNRS, Strasbourg, France). All three antibody preparations were used at various times to assess possible contamination of the MOG preparations with PLP.

Patients and blood samples. Venous heparinized blood samples were obtained from patients and staff of the Department of Neurology (Assaf Harofeh Hospital, Zerifin, Israel). The MS group was comprised of 22 consecutive outpatients and 2 inpatients ( 18 females, 6 males) who agreed upon request to be tested and were not under steroid treatment or other medication known to affect the immune system for at least 1 mo before the time of testing. 21 patients had definite MS and 3 had probable MS (32), and their Kurtzke's Expanded Disability Status Scale (EDSS) ranged from 2 to 8 (33) (Table II). The 16 patients and healthy individuals who comprised the control group ( 9 females, 7 males) were not under medications known to affect the immune system. None of the patients had other inflammatory diseases of the CNS.

Proliferation assays. PBLs were separated from $20 \mathrm{ml}$ of MS or control blood using Leucosep tubes as described by the manufacturer (Cat. no. ES 030 PP; Esquire Chemie, Switzerland). Isolated PBLs were cultured in microtiter wells in the absence or presence of the relevant antigens $(5-25 \mu \mathrm{g} / \mathrm{ml})$, essentially as described previously (34). Briefly, $2 \times 10^{5}$ cells/well were incubated in triplicate cultures in RPMI 1640 supplemented with $10 \mathrm{mM}$ Hepes buffer, $2 \mathrm{mM}$ glutamine (Bio-Lab, Jerusalem, Israel), 2-mercaptoethanol $\left(5 \times 10^{-5} \mathrm{M}\right)$, antibiotics (penicillin G [100 U/ml ] and streptomycin $[100 \mu \mathrm{g} / \mathrm{ml}]$ ), $1 \mathrm{mM}$ sodium pyruvate (Bio-Lab), $1 \%$ nonessential amino acids (Bio-Lab), and $10 \%$ fresh heat-inactivated autologous plasma. The cultures were incubated at $37^{\circ} \mathrm{C}$ in humidified air containing $7.5 \% \mathrm{CO}_{2}$. After $5 \mathrm{~d}$ of incubation, $\left[{ }^{3} \mathrm{H}\right]$ thymidine was added $(1 \mu \mathrm{Ci} /$ well $)$ for another $18 \mathrm{~h}$, and the cultures were harvested and counted using a Matrix 96 Direct beta counter (Packard Instr., Meriden, CT). The proliferative response is measured as the $\left[{ }^{3} \mathrm{H}\right]$ thymidine incorporation expressed as mean cpm of triplicate cultures. Stimulation indices (SI) are calculated as proliferative response in the presence of antigen, divided by proliferative response in the absence of antigen. Responses were initially assayed at various concentrations of the antigens and the optimal concentration range of responses to MOG, MBP, PLP, and MAG was determined to be between 5 and $25 \mu \mathrm{g} / \mathrm{ml}$. In view of the difficulties encountered to purify adequate quantities of MOG suitable for cell culture, the samples were subsequently tested only at two protein concentrations ( 5 and $25 \mu \mathrm{g} / \mathrm{ml}$ ) of the optimal concentration range; only the highest response observed is given in Results for each patient and control tested. Highest responses to MBP and PLP were generally observed at $5 \mu \mathrm{g} / \mathrm{ml}$; responses to MOG were generally highest at 25 $\mu \mathrm{g} / \mathrm{ml}$.

Statistical analysis. A two-way $\chi^{2}$ analysis was performed to compare the association between MS and responsiveness to each myelin antigen tested.

\section{Results}

Myelin antigen preparations. Highly purified myelin antigens were used in this study to ensure that reactivity to the various myelin antigens was indeed directed to each antigen being studied and not to small amounts of other myelin antigens possibly contaminating the preparations. Demonstration of a high degree of homogeneity was particularly important for the MOG preparations as such preparations are easily contaminated with PLP (15), which is present in myelin in considerably greater amounts than MOG ( $50 \%$ as compared with $\sim 0.01-0.05 \%$ ). In addition, such preparations should not contain appreciable levels of MBP, which has so far been shown to be the myelin antigen towards which most of the $T$ cell reactivity is directed (12). As demonstrated by immunoblotting with highly specific antibodies, the MOG preparations were not contaminated with even very low levels of PLP or MBP (Fig. $1 B$ ). Anti-HNK1 antibody-reactive bands could not be detected in MOG preparations at molecular masses expected for MAG (90-100 kD); however, such reactivity was observed for bands corresponding to MOG (Fig. $1 B$ ), the carbohydrate moiety of which contains the HNK1 epitope (35). Similarly, human MBP purified by the method of Dunkley and Carnegie (23) does not contain detectable levels of MOG, PLP, or MAG (Fig. $1 B$ ). Such a procedure yields an undegraded preparation, as indicated by immunoblotting with anti-MBP antibodies (Fig. $1 \mathrm{~B}$ ). Coomassie blue staining of a gel lane overloaded with purified human MAG reveals a single band (Fig. $1 A$ ) of a molecular mass compatible with that of dMAG $(\sim 90 \mathrm{kD} ; 25)$. No protein band could be detected at molecular masses expected for MBP ( 17-19 kD), PLP ( 30 and $24 \mathrm{kD})$, or MOG ( 28 and 58 kD) (Fig. 1 $A$ ). Because of availability, bovine, rather than human, PLP was used. It was felt that such a species difference 
A
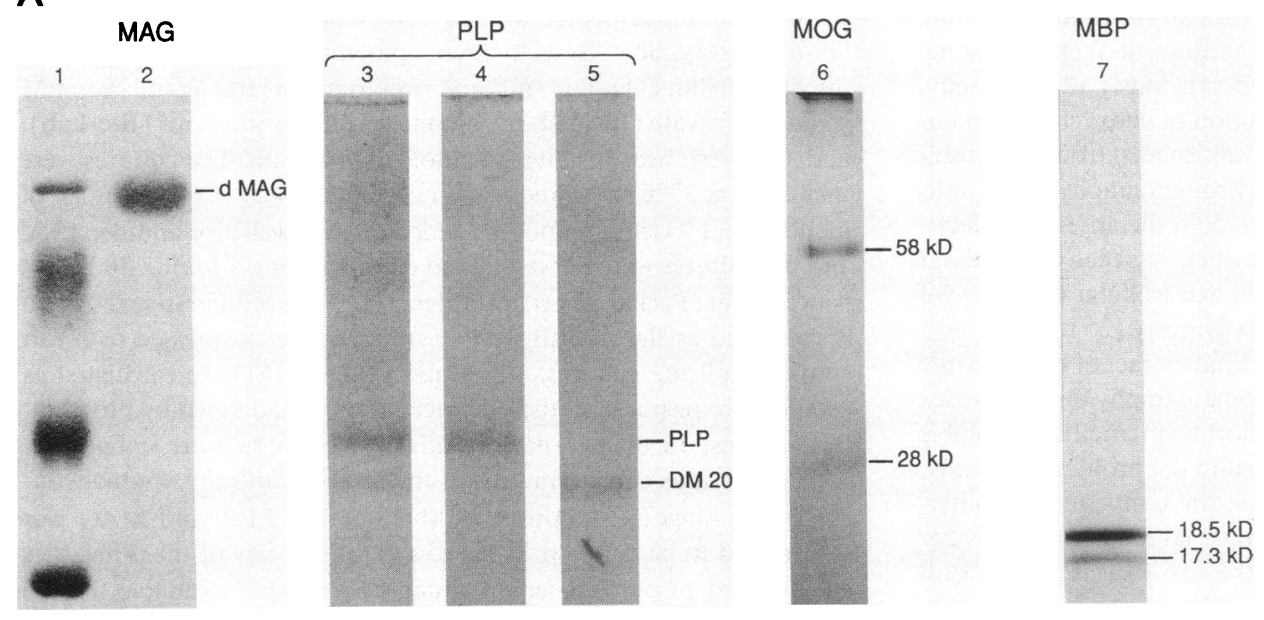

B
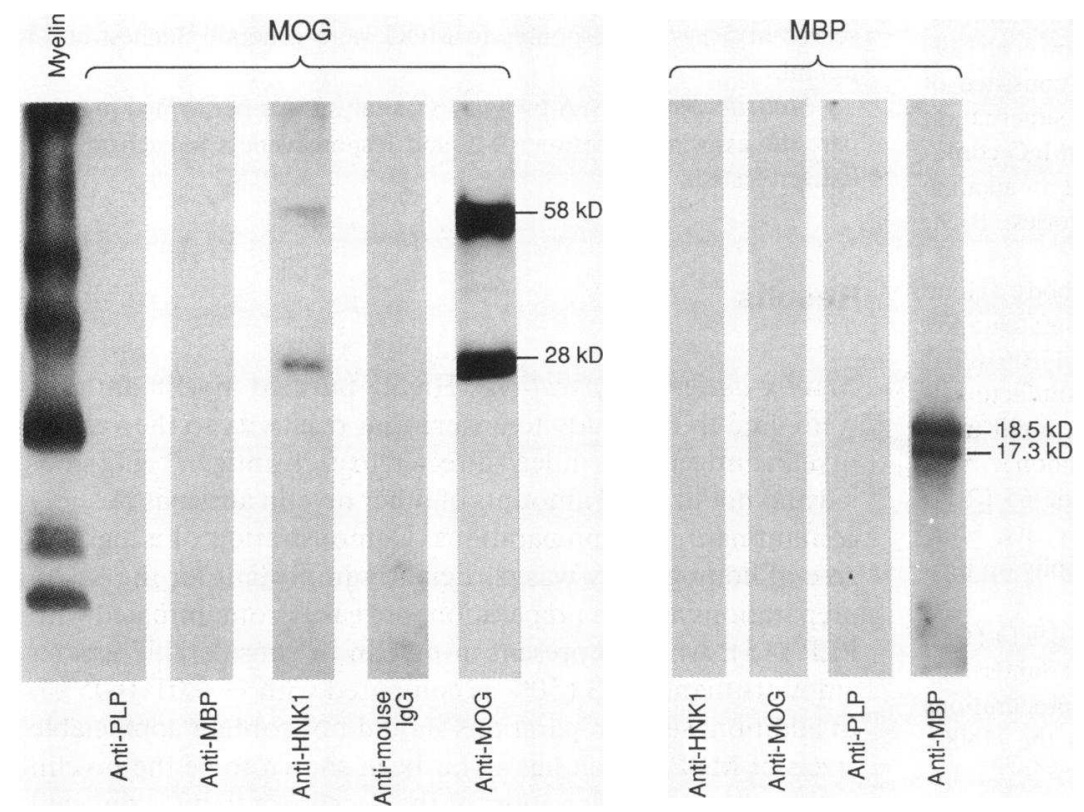

Figure 1. Demonstration of homogeneity of the myelin antigens used to detect proliferative responses by PBLs from MS patients and control subjects. $(A)$ Stained SDS-gels.

Lanes 1 and 2 represent molecular mass markers and purified dMAG $(3 \mu \mathrm{g})$, respectively, run on a $10 \%$ SDS gel and stained with Coomassie blue; molecular masses shown are, from the top: phosphorylase $b$ ( 94 $\mathrm{kD})$, albumin ( $66 \mathrm{kD})$, ovalbumin (45 kD), and carbonic anhydrase $(30 \mathrm{kD})$. These markers are not relevant for the other antigens. Lanes 3-5 represent silver-stained PLP preparations run on a $12 \%$ gel; the preparation used in this study is shown in lane 3 and contains both PLP isoforms: PLP and DM-20.

Lane 6 shows purified human MOG $(25 \mu \mathrm{g})$ run on a $15 \% \mathrm{gel}$; both 58 and 28-kD MOG bands can be seen Lane 7 shows purified human MBP ( $5 \mu \mathrm{g}$ ) run on a $15 \%$ gel, which comprises the 18.5- and the 17.3-kD isoforms present in adult. $(B) \mathrm{Im}$ munoblotting. Electrophoretograms of human myelin ( $30 \mu \mathrm{g} /$ lane $)$, purified human MOG ( $15 \mu \mathrm{g} /$ lane $)$, purified human MBP ( $1 \mu \mathrm{g} /$ lane $)$, or PLP $(10 \mu \mathrm{g} /$ lane $)$ were transferred onto nitrocellulose or polyvinyledene difluoride membrane and probed as described in Materials and Methods, with the various antibodies indicated. The myelin lane was a positive control to ensure that the anti-PLP antibody used to probe the human MOG and MBP preparations would detect PLP contamination if present. It was probed with an anti-PLP antibody that does not recognize DM-20 (60); in addition to the PLP band, higher and lower molecular mass forms were also detected as reported previously (61). was unlikely to have a marked effect on the potential $\mathrm{T}$ cell reactivity, in view of the very high homology between PLPs from various species (three amino acid differences between bovine and human PLP [36]). To ensure that we could indeed detect reactivity to bovine PLP with cells from another species and that conversion of PLP from solvent-soluble form to water-soluble form did not interfere with possible $T$ cell epitopes, the freshly converted PLP preparation was tested on a mouse $T$ cell line specific for a PLP peptide spanning amino acid residues 139-151, prepared as detailed previously (7). As shown in Table I, the water-soluble preparation of bovine PLP stimulated the PLP-specific mouse $T$ cell line, even when amounts as low as $1 \mu \mathrm{g}$ of the whole protein were used in the assay.

Proliferative responses to the myelin antigens by PBLs from $M S$ patients and control subjects. Levels of reactivity to myelin proteins in standard proliferation assays are notoriously low
$(12,37)$. Low, albeit reproducible, proliferative responses were also observed in the present study. Accordingly, a SI threshold of 2 was arbitrarily selected as representing a positive response. Table II shows the proliferative responses to the various myelin

Table I. Bovine PLP Preparation Stimulates Mouse T Line Cells Specific for PLP Peptide 139-151

\begin{tabular}{lccc}
\hline \multicolumn{1}{c}{ Antigen } & Dose & Proliferative response & SI \\
\hline & $\mu g$ & $c p m$ & \\
None & - & 678 & - \\
PLP peptide & 2.0 & 48,607 & 71 \\
PLP & 1.0 & 5,506 & 8.12 \\
PLP & 2.5 & 6,938 & 10.0 \\
& & & \\
\hline
\end{tabular}


Table II. Proliferative Responses to Myelin Antigens by PBLs from MS Patients

\begin{tabular}{|c|c|c|c|c|c|c|c|c|c|c|c|c|}
\hline \multirow[b]{3}{*}{ Patient } & \multirow[b]{3}{*}{ Sex } & \multirow[b]{3}{*}{ Age } & \multicolumn{5}{|c|}{ Clinical profile } & \multirow{2}{*}{\multicolumn{5}{|c|}{ Proliferative response* of PBLs to: }} \\
\hline & & & & & & & & & & & & \\
\hline & & & Diagnosis & Duration & Type $^{\ddagger}$ & Activity & (K.S) & None & MOG & MBP & MAG & PLP \\
\hline & & $y r$ & & & & & & & & & & \\
\hline MS1 & $\mathrm{F}$ & 43 & Definite & $20 \mathrm{yr}$ & RR & Rem. & 2.5 & $2,065 \pm 244$ & $10,008 \pm 372(4.8)$ & $1,874 \pm 257$ & $906 \pm 159$ & $2,095 \pm 21$ \\
\hline MS2 & $\mathrm{F}$ & 33 & Definite & $8 \mathrm{yr}$ & RR & Rem. & 2.5 & $460 \pm 103$ & $1,697 \pm 228$ & $972 \pm 34(2.1)$ & $298 \pm 83$ & $475 \pm 66$ \\
\hline MS3 & $\mathrm{F}$ & 41 & Probable & $1 \mathrm{wk}$ & $?$ & First attack & 5.5 & $5,491 \pm 3,469$ & $7,369 \pm 926$ & $10,079 \pm 2,146$ & $3,304 \pm 90$ & $7,301 \pm 2,997$ \\
\hline MS4 & $\mathrm{F}$ & 48 & Definite & $16 \mathrm{yr}$ & $\mathrm{CP}$ & - & 6.0 & $1,411 \pm 67$ & $19,540 \pm 638\left(13.8^{\S}\right)$ & $906 \pm 76$ & ND & $499 \pm 79$ \\
\hline MS5 & $\mathrm{F}$ & 55 & Probable & $19 \mathrm{yr}$ & $\mathbf{R R}$ & Rem. & 3.5 & $1,061 \pm 161$ & $1,475 \pm 894$ & $1,485 \pm 99$ & $1,122 \pm 105$ & $765 \pm 209$ \\
\hline MS6 & $\mathrm{F}$ & 66 & Definite & $3 \mathrm{yr}$ & $\mathrm{RR}$ & Rem. & 3.0 & $588 \pm 66$ & $4,482 \pm 1,479(7.6)$ & $2,481 \pm 475(4.2)$ & $426 \pm 17$ & $1,408 \pm 339(2.4)$ \\
\hline MS7 & $\mathrm{F}$ & 46 & Definite & $10 \mathrm{yr}$ & $\mathbf{R R}$ & Rem. & 7.0 & $304 \pm 114$ & $402 \pm 135$ & $329 \pm 36$ & $297 \pm 111$ & $224 \pm 108$ \\
\hline MS8 & $\mathrm{F}$ & 46 & Definite & $9 \mathrm{yr}$ & $\mathbf{R} \mathbf{R}$ & Rem. & 2.5 & $2,056 \pm 499$ & $1,955 \pm 5$ & $2,549 \pm 95$ & $1,356 \pm 171$ & $1,585 \pm 99$ \\
\hline MS9 & $\mathrm{F}$ & 40 & Definite & $7 \mathrm{yr}$ & RR & Rem. & 2.5 & $439 \pm 247$ & $1,090 \pm 285(2.5)$ & $367 \pm 152$ & $843 \pm 158$ & $374 \pm 4$ \\
\hline MS10 & $\mathbf{M}$ & 44 & Definite & $12 \mathrm{yr}$ & $\mathbf{R R}$ & Rem. & 6.0 & $444 \pm 27$ & $819 \pm 113$ & $1,028 \pm 181(2.3)$ & $599 \pm 70$ & $638 \pm 70$ \\
\hline MS11 & $\mathrm{F}$ & 17 & Definite & $2 \mathrm{yr}$ & RR & Rem. & 3.0 & $3,235 \pm 737$ & $6,868 \pm 567(2.1)$ & $7,336 \pm 1,693(2.2)$ & $2,379 \pm 158$ & $9,935 \pm 1,497(3.0)$ \\
\hline MS12 & $\mathbf{M}$ & 55 & Definite & $19 \mathrm{yr}$ & $\mathrm{CP}$ & - & 8.0 & $288 \pm 35$ & $562 \pm 113$ & $432 \pm 55$ & $317 \pm 61$ & $364 \pm 74$ \\
\hline MS 13 & $\mathrm{~F}$ & 42 & Definite & $2 \mathrm{yr}$ & $\mathbf{R R}$ & Rem. & 5.0 & $103 \pm 5$ & $256 \pm 105$ & $104 \pm 4$ & ND & $202 \pm 19$ \\
\hline MS14 & $\mathrm{F}$ & 40 & Definite & $6 \mathrm{yr}$ & RR & Rem. & 2.0 & $1,808 \pm 426$ & $6,151 \pm 108(3.4)$ & $2,019 \pm 219$ & $940 \pm 212$ & $3,343 \pm 298$ \\
\hline MS15 & $\mathrm{F}$ & 46 & Definite & $26 \mathrm{yr}$ & $\mathbf{R R}$ & Rem. & 4.0 & $1,249 \pm 322$ & $670 \pm 277$ & $1,443 \pm 433$ & $236 \pm 37$ & $888 \pm 635$ \\
\hline MS16 & $\mathrm{F}$ & 51 & Definite & $16 \mathrm{yr}$ & $\mathbf{R} \mathbf{R}$ & Rem. & 7.0 & $393 \pm 25$ & $764 \pm 164$ & $438 \pm 59$ & $485 \pm 101$ & $435 \pm 101$ \\
\hline MS17 & $F$ & 42 & Definite & $15 \mathrm{yr}$ & $\mathbf{R} \mathbf{R}$ & Rem. & 2.5 & $336 \pm 61$ & $386 \pm 20$ & $432 \pm 165$ & $246 \pm 31$ & $331 \pm 80$ \\
\hline MS18 & $\mathrm{F}$ & 36 & Definite & $12 \mathrm{yr}$ & $\mathrm{RR}$ & Rem. & 2.0 & $594 \pm 103$ & $1,313 \pm 39(2.2)$ & $908 \pm 104$ & $490 \pm 258$ & $615 \pm 199$ \\
\hline MS19 & $\mathbf{M}$ & 33 & Definite & $9 \mathrm{yr}$ & $\mathbf{R R}$ & Rem. & 3.5 & $198 \pm 18$ & $1,471 \pm 387(7.4)$ & $238 \pm 86$ & ND & $201 \pm 93$ \\
\hline MS20 & $\mathrm{F}$ & 43 & Definite & $21 \mathrm{yr}$ & RR & Rem. & 4.0 & $211 \pm 73$ & $1,077 \pm 125$ & $302 \pm 43$ & $263 \pm 153$ & $330 \pm 86$ \\
\hline MS21 & $\mathbf{M}$ & 52 & Definite & $24 \mathrm{yr}$ & RR & Rem. & 2.5 & $1,318 \pm 288$ & $1,534 \pm 777$ & $945 \pm 98$ & $277 \pm 40$ & $507 \pm 134$ \\
\hline MS22 & M & 47 & Definite & $16 \mathrm{yr}$ & RR & Relapse & 2.5 & $1,022 \pm 12$ & $914 \pm 39$ & $949 \pm 162$ & $482 \pm 31$ & $530 \pm 153$ \\
\hline MS23 & $\mathbf{M}$ & 56 & Definite & $21 \mathrm{yr}$ & $\mathrm{CP}$ & - & 8.0 & $477 \pm 115$ & $1,438 \pm 454(3.0)$ & $503 \pm 121$ & $392 \pm 63$ & $456 \pm 143$ \\
\hline MS24 & $\mathrm{F}$ & 50 & Probable & $20 \mathrm{yr}$ & $\mathbf{R}$ & Rem. & ND & $452 \pm 162$ & $3,318 \pm 457(7.3)$ & $1,394 \pm 625(3.0)$ & ND & $377 \pm 96$ \\
\hline
\end{tabular}

* Expressed as mean cpm of incorporated $\left[{ }^{3} \mathrm{H}\right]$ thymidine $\pm \mathrm{SD}$. Where significantly increased $(\geq 2)$, SI is given in parentheses.

${ }^{\ddagger} \mathrm{RR}$, relapsing-remitting; $\mathrm{CP}$, chronic progressive; Rem., remission.

${ }^{8}$ Tested on fetal calf serum.

antigens tested by PBLs from MS patients. As can be seen, the greatest incidence of response observed in MS patients was to MOG. Of the 24 MS patients tested, 12 showed a positive response to this antigen, whereas only 5 and 2 responded to MBP and PLP, respectively (Table II). It is interesting to note that reactivity to MOG was not only more frequent in MS patients than reactivity to MBP and PLP, but the extent of reactivity was also generally higher (see Table II). In this population of MS patients, only one patient (MS9) responded to MAG; however, the stimulation $(\mathrm{SI}=1.92)$ did not reach our threshold of significance. Although reactivity to MOG of PBLs from MS patients was also seen in combination with reactivity to other myelin antigens, $>66 \%(8 / 12)$ of the MS patients responding to MOG reacted to this antigen exclusively (Table II). Of the five MS patients that showed a positive response to MBP (Table II), only one (patient MS10) reacted with MBP exclusively; the other four (patients MS2, MS6, MS11, and MS24) responded to MOG also and two of these (patients MS6 and MS1 1 ) had PLP-reactive PBLs as well ( Table II). Reactivity to PLP by PBLs from MS patients was only observed in combination with reactivity to other myelin antigens, MOG and MBP (patients MS6 and MS11; Table II). Thus, only two MS patients reacted to a combination of three myelin antigens, and reactivity to all four myelin antigens tested was not observed.

The incidence of MOG reactivity measured in individuals of the control group (Table III) was significantly lower than that measured in MS patients as, of the 16 controls tested, only 1 responded (Table III, subject $\mathrm{C} 11$ ). It should be noted that PBLs from this control individual (C11) also reacted to MBP.
Reactivity to MBP was also observed in two other control individuals (Table III, C8 and C15). Positive responses ( $\mathrm{SI} \geq 2$ ) to PLP and MAG were not observed with control PBLs (Tables III and IV).

Statistical analysis of the association between MS and responsiveness to each myelin antigen tested indicated that the association between MS and responsiveness to MOG was highly significant $\left(\chi^{2}=8.37\right.$, degree of freedom [d.f.] $=1, p$ $<0.004$; Table IV). There was no statistically significant association between MS and responsiveness to the other myelin antigens in the MS population tested in this study.

\section{Discussion}

In view of the encephalitogenic activity of purified MBP and PLP (reviewed in reference 38 ) and, more specifically, because MBP- or PLP-specific T cells are sufficient to cause EAE (711), these two most abundant myelin proteins have been regarded as prime candidate antigens to elicit relevant immune responses in MS. However, and in contrast to this widely accepted notion, our present analysis shows that the quantitatively minor myelin protein, MOG, may be at least as important an antigen in MS as MBP or PLP. Indeed, the fact that 12 of 24 patients $(50 \%)$ reacted to MOG while only 5 and 2 patients reacted to MBP and PLP, respectively, may point to MOG as a primary candidate antigen in MS. That only 1 of the 16 control individuals reacted to MOG further supports the postulate that reactivity to MOG plays a role in the pathogenesis of MS. 
Table III. Proliferative Responses to Myelin Antigens by PBLs from Control Individuals

\begin{tabular}{|c|c|c|c|c|c|c|c|c|}
\hline \multirow[b]{2}{*}{ Control } & \multirow[b]{2}{*}{ Sex } & \multirow[b]{2}{*}{ Age } & \multirow[b]{2}{*}{ Health status } & \multicolumn{5}{|c|}{ Proliferative response* of PBLs to: } \\
\hline & & & & None & MOG & MBP & MAG & PLP \\
\hline & & $y r$ & & & & & & \\
\hline $\mathrm{Cl}$ & $\mathbf{F}$ & 47 & Epilepsy & $2,203 \pm 86$ & $516 \pm 91$ & $1,182 \pm 99$ & $178 \pm 31$ & $1,478 \pm 241$ \\
\hline $\mathrm{C} 2$ & $\mathbf{M}$ & 18 & Brachial plexitis & $6,532 \pm 1,029$ & $6,981 \pm 1143$ & $6,795 \pm 1,228$ & $709 \pm 64$ & $4,546 \pm 140$ \\
\hline $\mathrm{C} 3$ & $\mathbf{M}$ & 43 & Epilepsy & $1,552 \pm 8$ & $2,409 \pm 59$ & $1,864 \pm 307$ & $911 \pm 183$ & $1,666 \pm 98$ \\
\hline $\mathrm{C} 4$ & $\mathbf{M}$ & 61 & CVA & $1,237 \pm 34$ & $703 \pm 74$ & $1,108 \pm 176$ & $345 \pm 65$ & $527 \pm 168$ \\
\hline $\mathrm{C} 5$ & $\mathbf{M}$ & 46 & Epilepsy & $5,103 \pm 740$ & $5,364 \pm 587$ & $6,529 \pm 130$ & $3,327 \pm 577$ & $4,400 \pm 215$ \\
\hline $\mathrm{C} 6$ & $\mathbf{F}$ & 45 & Dismyelinating disease & $3,231 \pm 191$ & $4,764 \pm 46$ & $1,268 \pm 267$ & $666 \pm 106$ & $1,728 \pm 298$ \\
\hline $\mathrm{C} 7$ & $\mathrm{~F}$ & 19 & Healthy & $2,505 \pm 269$ & $2,025 \pm 790$ & $4,695 \pm 484$ & $482 \pm 37$ & $867 \pm 125$ \\
\hline $\mathrm{C} 8$ & $F$ & 20 & Healthy & $690 \pm 144$ & $986 \pm 6$ & $1,457 \pm 284(2.1)$ & $581 \pm 52$ & $949 \pm 145$ \\
\hline C9 & $\mathrm{F}$ & 70 & Parkinson's disease & $236 \pm 58$ & $370 \pm 104$ & $367 \pm 201$ & $307 \pm 103$ & $239 \pm 18$ \\
\hline $\mathrm{C} 10$ & $\mathbf{M}$ & 42 & Healthy & $1,149 \pm 389$ & $1,157 \pm 1$ & $1,031 \pm 161$ & $381 \pm 77$ & $604 \pm 53$ \\
\hline $\mathrm{C} 11$ & $\mathrm{~F}$ & 46 & Tension headache & $342 \pm 34$ & $790 \pm 32(2.3)$ & $797 \pm 164(2.3)$ & ND & $651 \pm 701$ \\
\hline $\mathrm{C} 12$ & $\mathbf{M}$ & 42 & Tension headache & $11,482 \pm 3,252$ & $9,510 \pm 743$ & $14,258 \pm 905$ & ND & $7,757 \pm 572$ \\
\hline $\mathrm{C} 13$ & $\mathbf{M}$ & 45 & Meningioma & $5,128 \pm 1,826$ & $4,905 \pm 79$ & $4,891 \pm 109$ & ND & $4,288 \pm 183$ \\
\hline $\mathrm{C} 14$ & $\mathrm{~F}$ & 58 & Healthy & $1,420 \pm 329$ & $1,438 \pm 191$ & $2,027 \pm 301$ & ND & $1,124 \pm 135$ \\
\hline $\mathrm{C} 15$ & $\mathbf{F}$ & 42 & Epilepsy, brain atrophy & $1,248 \pm 154$ & $1,065 \pm 207$ & $2,287 \pm 179$ & $454 \pm 130$ & $1,547 \pm 137$ \\
\hline $\mathrm{C} 16$ & $\mathbf{F}$ & 45 & Healthy & $1,412 \pm 157$ & $1,260 \pm 126$ & $833 \pm 67$ & $562 \pm 48$ & $1,552 \pm 212$ \\
\hline
\end{tabular}

* Expressed as mean cpm of incorporated $\left[{ }^{3} \mathrm{H}\right]$ thymidine. Where significantly increased $(\geq 2)$, SI is given in parentheses.

In this study, few MS patients $(5 / 24 ; 20.8 \%)$ were found to show positive cell-mediated responses to MBP, and a similar proportion $(2 / 16 ; 12.5 \%)$ of control individuals also reacted to this antigen. Although a low frequency of MBP-responsive MS patients was unexpected, in view of the data of some previously published studies (39-43) and the assumption that MS is associated with the response to MBP, these results are in line with other studies where PBL sensitization to MBP could be detected in some MS patients, but also in patients with other neurological diseases and in healthy controls $(37,44-50)$. Similarly, our data on PLP reactivity, whereby 2 of 24 MS patients reacted positively to this antigen, are in agreement with some studies but in disagreement with others, as diverging results have been obtained by various groups assessing PLP sensitization in MS. Thus, data reported by Trotter et al. (48) showed sensitization to PLP in 6 of 16 patients with chronic progressive MS and 3 of 15 patients with relapsing remitting MS; Sun et al. (51), using an immunospot assay to detect IFN- $\gamma$ secretion by antigen-specific lymphocytes, reported increased numbers of PLP-reactive $T$ cells in both blood and cerebrospinal fluid

Table IV. Summary of Proliferative Responses to Myelin Antigens

\begin{tabular}{lcc}
\hline & \multicolumn{2}{c}{ Frequency of positive response by: } \\
\cline { 2 - 3 } Stimulating antigen & MS PBLs (\%) & Control PBLs (\%) \\
\hline MOG & $12 / 24(50)^{*}$ & $1 / 16(6.25)$ \\
MBP & $5 / 24(20.8)$ & $2 / 16(12.5)$ \\
MAG & $0 / 20(0)$ & $0 / 12(0)$ \\
PLP & $2 / 24(8.3)$ & $0 / 16(0)$ \\
MOG and MBP & $4 / 24(16.6)$ & $1 / 16(6.25)$ \\
MOG and PLP & $2 / 24(8.3)$ & $0 / 16(0)$
\end{tabular}

${ }^{*} P<0.004$ compared with control group.
(CSF) of most MS patients tested. Although no differences in frequencies of circulating T cells to PLP were found by Chou et al. (49) between MS patients and control subjects, the same study showed a significantly higher frequency of PLP-reactive $T$ cells in the CSF of MS patients than in the CSF of individuals with other neurological diseases (49). In contrast, Hafler et al. (45) could not detect PLP reactivity by any of $57 \mathrm{~T}$ cell clones derived from autopsied MS plaque tissue, nor by any of 235 clones derived from the CSF and 126 clones from the peripheral blood of other subjects with MS. In the study of Johnson et al. (37), reactivity to PLP could only be uncovered in a few MS patients after deletion of the T8 (cytotoxic/suppressor) lymphocyte subset from PBLs; however, a significantly elevated number of patients with other neurological diseases reacted to this antigen whether or not T8-positive cells had been removed (37). Ota et al. (47) observed more reactivity to PLP, albeit of no statistical significance, in patients with MS compared with patients with other neurological diseases. Very little reactivity to MAG was observed in our study as PBLs from only one MS patient (MS9) responded, albeit not significantly $(\mathrm{SI}=1.92)$. This is in contrast with the study of Johnson et al. (37), where low-level MAG sensitization was seen to occur in some active MS patients, and the study of Zhang et al. (52), where 7 of the 11 MS patients tested responded to this antigen, 2 of them exclusively. Higher numbers of MAG-reactive cells were also reported in blood and CSF of MS patients by Link et al. (53) using the immunospot assay. Controversial results obtained with MAG as well as with the other myelin antigens tested may reflect not only differences in antigenic preparations and/or amounts of antigen used in the assays (12), but also experimental differences in protocols followed to detect sensitization by assessing proliferative responses to purified antigens. An alternative explanation for variable results is that MS may in fact be associated with more than one myelin antigen so that the primary target may be different in different patients. Further- 
more, and as demonstrated in EAE induced with purified MBP, sensitization to one myelin antigen can lead to the induction of reactivity towards additional CNS autoantigens (54), which could perhaps override reactivity to the primary target.

MOG has recently attracted a lot of interest in view of its possible role as a target antigen in immune-mediated demyelinating diseases (reviewed in reference 55). Thus, humoral immunity to MOG has been correlated with demyelinating activity in chronic relapsing EAE (18), and the presence of antibodies to MOG within CNS tissue results in extensive demyelination in vivo (19-21) and in vitro $(22,56)$. In addition to the possible role of anti-MOG antibodies in mediating demyelination, these studies demonstrated the immunogenic potential of MOG, which, despite being present in very low amounts in the CNS $(15,17)$, can induce important, detectable immune responses in animals injected for EAE with spinal cord or brain homogenates $(18,57)$. That MOG may be a primary target for autoimmune responses associated with demyelinating diseases is also strongly suggested by our preliminary results whereby Lewis rats injected with purified human MOG develop a demyelinating and relapsing EAE-like disease with concomitant production of increasing levels of anti-MOG antibody in the serum, to the exclusion of detectable humoral immune response to other myelin proteins (Kerlero de Rosbo, N., T. Johns, K. Menon, S. Abo, and C. Bernard, manuscript in preparation). Because MOG, a highly hydrophobic molecule present in very small quantities in CNS tissue $(15,58)$, is extremely difficult and cumbersome to purify in quantities and quality required to analyze specific $T$ cell reactivity by standard assays, studies to assess sensitization to this antigen have not been forthcoming. However, in one study, where problems associated with purification of MOG were circumvented by using the immunospot assay, MOG-reactive T cells were observed in peripheral blood of most of the 14 MS patients studied, whereas only $25 \%$ of the 28 controls showed reactivity (59). Nevertheless, this study is, to the best of our knowledge, the first report of an investigation of the proliferative response to highly purified MOG by PBLs from MS patients. As yet, it is difficult to correlate reactivity to MOG with a particular status of the disease. Neither average duration of the disease (12.08 \pm 6.9 and $15.2 \pm 6.5 \mathrm{yr}$ for responders and nonresponders, respectively) nor average age of onset ( $30 \pm 11$ and $32.5 \pm 5.4$ yr for responders and nonresponders, respectively) appear to be factors influencing the response to MOG of PBLs from MS patients. Most importantly, the responsiveness to MOG by MS PBLs was not restricted to a particular subgroup of MS patients as it was observed in definite as well as probable MS, in either the relapsing remitting or the chronic-progressive type. Two of the three chronic progressive MS patients ( Table II, MS4 and MS23) responded to MOG, but not to the other three myelin antigens tested, and the two patients with an acute attack (Table II, MS3 and MS22) did not show any reactivity to MOG. However, due to the small number of patients in each subgroup, it is difficult to draw any conclusion correlating MOG responsiveness with disease stage. Nevertheless, our study demonstrates not only that assessment of the reactivity to minor myelin antigens may be highly relevant to the understanding of MS pathogenesis, but also emphasizes the importance of testing reactivity to all potential antigens in parallel, in the attempt to assign a primary role to one or the other possible targets. In conclusion, predominance of reactivity to MOG in MS in the context of comparatively rarer reactivity to the other myelin antigens tested concomitantly in the same patients shows that MOG may be as important as MBP or PLP in disease pathogenesis and may indeed be the primary target myelin antigen in at least some MS patients. Our observation that MOG itself may also be encephalitogenic (Kerlero de Rosbo, N., T. Johns, K. Menon, S. Abo, and C. Bernard, manuscript in preparation) strongly supports this postulate and emphasizes the relevance of immune responses to MOG in MS. Persistence of MOG reactivity together with reactivity to other myelin antigens could point to a greater role for immune recognition of MOG in disease initiation with broadening of the autoimmune response to additional determinants on this and/ or other autoantigens as the disease progresses. Further studies are in progress to investigate this hypothesis.

\section{Acknowledgments}

We thank Dr. S. Abo and Ms. A. Alafaci for their help in the purification of human MOG; Prof. P. R. Carnegie for monoclonal anti-MBP antibody, clone 65(2-1); Prof. W. B. Macklin and Dr. E. Trifilieff for polyclonal anti-PLP antibodies; and Dr. M. Webb for cells of clone 8-18C5 producing monoclonal anti-MOG antibody.

This work was supported by the National Multiple Sclerosis Society of Australia (NMSSA), the National Health and Medical Research Council of Australia, the Israel Ministry of Health, the Lilly and Herman Schilling Foundation, the Israeli Academy of Sciences and Humanities, National Institutes of Health grants NS-13649 and NS-16945 (Javits award), and the Department of Mental Retardation of the Commonwealth of Massachusetts (contract 100220023SC). N. Kerlero de Rosbo is a NMSSA Research Fellow. A. Ben-Nun is the incumbent of the Swig-Weiler Career Development Chair at the Weizmann Institute of Science.

\section{References}

1. Raine, C. 1984. Biology of disease. The analysis of autoimmune demyelination: its impact upon multiple sclerosis. Lab. Invest. 50:608-635.

2. Traugott, U., E. L. Reinherz, and C. Raine. 1983. Multiple sclerosis: distribution of $\mathrm{T}$ cells, $\mathrm{T}$ cell subsets, and Ia-positive macrophages in lesions of different ages. J. Neuroimmunol. 4:201-221.

3. Boos, J., M. M. Esiri, W. W. Tourtellotte, and D. Y. Mason. 1983. Immunohistochemical analysis of $\mathrm{T}$ lymphocyte subsets in the central nervous system in chronic progressive multiple sclerosis. J. Neurol. Sci. 62:219-232.

4. McCallum, K., M. M. Esiri, W. W. Tourtellotte, and J. Boos. 1987. T cell subsets in multiple sclerosis. Gradients at plaque borders and differences in nonplaque regions. Brain. 110:1297-1308.

5. Raine, C. 1991. Multiple sclerosis: a pivotal role for the $\mathrm{T}$ cell in lesion development. Neuropathol. Appl. Neurobiol. 17:265-274.

6. Prineas, J. W. 1985. The neuropathology of multiple sclerosis. In Handbook of Clinical Neurology, vol. 3: Demyelinating Diseases. Vinken, P. J., G. W. Bruyn, and H. L. Klawans, editors. Elsevier Science Publishing Co., Inc., New York. 213-257.

7. Ben Nun, A., H. Wekerle, and I. R. Cohen. 1981. The rapid isolation of clonable antigen-specific $\mathrm{T}$ lymphocyte lines capable of mediating autoimmune encephalomyelitis. Eur. J. Immunol. 11:195-199.

8. Mokhtarian, F., D. E. McFarlin, and C. S. Raine. 1984. Adoptive transfer of myelin basic protein-specific $\mathrm{T}$ cells produces chronic relapsing demyelinating disease in mice. Nature (Lond.). 309:356-358.

9. Satoh, J., K. Sakai, M. Endoh, F. Koike, T. Kunishita, T. Namikawa, T. Yamamura, and T. Tabira. 1987. Experimental allergic encephalomyelitis mediated by murine encephalitogenic $\mathrm{T}$ cell lines specific for myelin proteolipid apoprotein. J. Immunol. 138:179-184.

10. van der Veen, R. C., J. L. Trotter, H. B. Clark, and J. A. Kapp. 1989. The adoptive transfer of chronic relapsing experimental allergic encephalomyelitis with lymph node cells sensitized to myelin proteolipid protein. J. Neuroimmunol. 21:183-191.

11. Kuchroo, V. K., R. A. Sobel, T. Yamamura, E. Greenfield, M. Dorf, and M. B. Lees. 1991. Induction of experimental allergic encephalomyelitis by myelin proteolipid protein-specific T cell clones and synthetic peptides. Pathobiology. 59:305-312.

12. Richert, J. 1992. Human T cell recognition of myelin basic protein peptides. In Myelin: Biology and chemistry. R. E. Martenson, editor. CRC Press, Inc., Boca Raton. 833-847. 
13. Lees, M. B., and S. W. Brostoff. 1984. Proteins of myelin. In Myelin, 2nd edition. P. Morell, editor. Plenum Publishing Corporation. New York. 197-224.

14. Brady, R. O., and R. H. Quarles. 1988. Developmental and pathophysiological aspects of the myelin-associated glycoprotein. Cell. Mol. Neurobiol. 8:139-148.

15. Amiguet, P., M. V. Gardinier, J.-P. Zanetta, and J.-M. Matthieu. 1992. Purification and partial structural and functional characterization of mouse myelin/oligodendrocyte glycoprotein. J. Neurochem. 58:1676-1682.

16. Burger, D., and A. J. Steck. 1993. Neuropathies associated with anti-myelin antibodies. In Immunology of Neuromuscular Diseases. R. Hohlfeld, editor. Kluver Academic Publishers, Dordrecht. In press.

17. Linington, C., M. Webb, and P. L. Woodhams. 1984. A novel myelin-associated glycoprotein defined by a mouse monoclonal antibody. J. Neuroimmunol. 6:387-396.

18. Linington, C., and H. Lassmann. 1987. Antibody responses in chronic relapsing experimental allergic encephalomyelitis: correlation of serum demyelinating activity with antibody titre to the myelin/oligodendrocyte glycoprotein (MOG). J. Neuroimmunol. 17:61-69.

19. Lassmann, H., and C. Linington. 1987. The role of antibodies against myelin surface antigens in demyelination in chronic EAE. In A Multidisciplinary Approach to Myelin Diseases. G. S. Crescenzi, editor. Plenum Publishing Corporation, New York. 219-225.

20. Schluesener, H. J., R. A. Sobel, C. Linington, and H. L. Weiner. 1987. A monoclonal antibody against a myelin oligodendrocyte glycoprotein induces relapses and demyelination in central nervous system autoimmune disease. J. Immunol. 139:4016-4021.

21. Linington, C., M. Bradl, H. Lassmann, C. Brunner, and K. Vass. 1988. Augmentation of demyelination in rat acute allergic encephalomyelitis by circulating mouse monoclonal antibodies directed against a myelin/oligodendrocyte glycoprotein. Am. J. Pathol. 130:443-454.

22. Kerlero de Rosbo, N., P. Honegger, H. Lassmann, and J.-M. Matthieu. 1990. Demyelination induced in aggregating brain cell cultures by a monoclonal antibody against myelin/oligodendrocyte glycoprotein. J. Neurochem. 55:583587.

23. Dunkley, P. R., and P. R. Carnegie. 1974. Isolation of myelin basic proteins. In Research Methods in Neurochemistry, vol. 2. N. Marks and R. Rodnight, editors. Plenum Publishing Corporation, New York. 219-245.

24. Kerlero de Rosbo, N., P. R. Carnegie, C. C. A. Bernard, and D. S. Linthicum. 1984. Detection of various forms of brain myelin basic protein in vertebrates by electroimmunoblotting. Neurochem. Res. 9:1359-1369.

24a. Abo, S., C. C. A. Bernard, M. Webb, T. G. Johns, A. Alafaci, L. D. Ward, R. J. Simpson, and N. Kerlero de Rosbo. 1993. Preparation of highly purified human myelin oligodendrocyte glycoprotein in quantities sufficient for encephalitogenicity and immunogenicity studies. Biochem. Mol. Biol. Int. 30:945-958.

25. Burger, D., M. Simon, G. Perruisseau, and A. J. Steck. 1990. The epitope(s) recognised by HNK-1 antibody and IgM paraprotein in neuropathy is present on several $\mathrm{N}$-linked oligosaccharide structures on human $\mathrm{PO}$ and myelinassociated glycoprotein. J. Neurochem. 54:1569-1575.

26. Folch, J., M. B. Lees, and G. H. Sloane Stanley. 1957. A simple method for isolation and purification of total lipids from animal tissues. J. Biol. Chem 266:497-509.

27. Bizzozero, O., M. Besio-Moreno, J. M. Pasquini, E. F. Soto, and C. J. Gomez. 1982. Rapid purification of proteolipids from rat subcellular fractions by chromatography on a lipophilic dextran gel. $J$. Chromatogr. 27:33-44.

28. Laemmli, U. K. 1970. Cleavage of structural proteins during the assembly of the head of bacteriophage T4. Nature (Lond.). 227:680-685.

29. Yamamura, T., J. Konola, H. Wekerle, and M. B. Lees. 1991. Monoclonal antibodies against myelin proteolipid protein: Identification and characterization of two major determinants. J. Neurochem. 57:1671-1680.

30. Carnegie, P. R., C. A. Dowse, and D. S. Linthicum. 1983. Antigenic determinant recognized by a monoclonal antibody to human myelin basic protein. J. Neuroimmunol. 5:125-134.

31. McGarry, R. C., S. L. Helfand, R. H. Quarles, and J. C. Roder. 1983. Recognition of myelin-associated glycoprotein by the monoclonal antibody HNK-1. Nature (Lond.). 306:376-378.

32. Poser, C. M., D. W. Paty, L. Scheinberg, W. I. McDonald, F. A. Davis, G. C. Ebers, K. P. Johnson, W. A. Sibley, D. H. Silberberg, and W. W. Tourtellotte. 1983. New diagnostic criteria for multiple sclerosis: Guidelines for research protocols. Ann. Neurol. 13:227-231.

33. Kurtzke, J. F. 1983. Rating neurologic impairment in multiple sclerosis: an expanded disability status scale (EDSS). Neurology. 33:144-152.

34. Ben Nun, A., and I. R. Cohen. 1982. Experimental autoimmune encephalomyelitis (EAE) mediated by $\mathrm{T}$ cell line: process of selection of lines and characterization of the cells. J. Immunol. 129:303-308.

35. Burger, D., A. J. Steck, C. C. A. Bernard, and N. Kerlero de Rosbo. 1993 Human myelin/oligodendrocyte glycoprotein: a new member of the L2/HNK-1 family. J. Neurochem. 61:1822-1827.

36. Macklin, W. B. 1992. The myelin proteolipid protein gene and its expression. In Myelin: Biology and chemistry, R. E. Martenson, editor. CRC Press, Inc., Boca Raton. 257-276.

37. Johnson, D., D. A. Hafler, R. J. Fallis, M. B. Lees, R. O. Brady, R. H. Quarles, and H. L. Weiner. 1986. Cell-mediated immunity to myelin-associated glycoprotein, proteolipid protein and myelin basic protein in multiple sclerosis. J. Neuroimmunol. 13:99-108.

38. Bernard, C. C. A., T. Mandel, and I. R. Mackay. 1992. Experimental models of human autoimmune disease: Overview and prototypes. In The $\mathrm{Au}$ toimmune Diseases II. N. Rose and I. R. Mackay, editors. Academic Press, New York. 47-106.

39. Colby, S. P., W. Sheremata, B. Bain, and E. H. Eylar. 1977. Cellular hypersensitivity in attacks of multiple sclerosis. Neurology. 27:132-139.

40. Lisak, R. P., B. Zweiman, D. Waters, H. Koprowski, and D. E. Pleasure. 1978. Cell-mediated immunity to measles, myelin basic protein and central nervous system extract in multiple sclerosis. Neurology. 28:798-803.

41. Tournier-Lasserve, E., G. A. Hashim, and M.-A. Bach. 1988. Human T-cell response to myelin basic protein in multiple sclerosis patients and healthy subjects. J. Neurosci. Res. 19:149-152.

42. Baxevanis, C. N., G. J. Reclos, C. Servis, E. Anastasopoulos, P. Arsenis, A. Katsiyiannis, N. Matikas, J. D. Lambris, and M. Papamichail. 1989. Peptides of myelin basic protein stimulate $\mathrm{T}$ lymphocytes from patients with multiple sclerosis. J. Neuroimmunol. 22:23-30.

43. Vandenbark, A. A., Y. K. Chou, D. Bourdette, R. Whitam, J. Chilgren, C.-H. J. Chou, G. Konat, M. Vainiene, and H. Offner. 1989. Human T-lymphocyte response to myelin basic protein: selection of T-lymphocyte lines from MBPresponsive donors. J. Neurosci. Res. 23:21-30.

44. Lisak, R. P., B. Zweiman, J. B. Burns, A. Rostami, and D. H. Silberberg. 1984. Immune responses to myelin antigens in multiple sclerosis. Ann. NY Acad. Sci. 436:221-230.

45. Hafler, D. A., D. S. Benjamin, J. Burks, and H. L. Weiner. 1987. Myelin basic protein and proteolipid protein reactivity of brain and cerebrospinal fluidderived $\mathrm{T}$ cell clones in multiple sclerosis and postinfectious encephalomyelitis. J. Immunol. 139:68-72.

46. Burns, J. B., and K. Littlefield. 1989. Human T lymphocytes reactive with whole myelin recognize predominantly myelin basic protein. J. Neuroimmunol. 24:67-74.

47. Ota, K., M. Matsui, E. L. Milford, G. A. Mackin, H. L. Weiner, and D. A. Hafler. 1990. T-cell recognition of an immunodominant myelin basic protein epitope in multiple sclerosis. Nature (Lond.). 346:183-187.

48. Trotter, J. L., W. F. Hickey, R. C. van der Veen, and L. Sulze. 1991 Peripheral blood mononuclear cells from multiple sclerosis patients recognize myelin proteolipid protein and selected peptides. J. Neuroimmunol. 33:55-62.

49. Chou, Y. K., D. N. Bourdette, H. Offner, R. Whitham, R.-Y. Wang, G. A Hashim, and A. A. Vandenbark. 1992. Frequency of T cells specific for myelin basic protein and myelin proteolipid protein in blood and cerebrospinal fluid in multiple sclerosis. J. Neuroimmunol. 38:105-114.

50. Jingwu, Z., R. Medaer, G. A. Hashim, Y. Chin, E. van den Berg-Loonen, and J. C. Raus. 1992. Myelin basic protein-specific T lymphocytes in multiple sclerosis and controls: precursor frequency, fine specificity and cytotoxicity. Ann Neurol. 32:330-338

51. Sun, J.-B., T. Olsson, W.-Z. Wang, B.-G. Xiao, V. Kostulas, V. Fredrikson, H.-P. Ekre, and H. Link. 1991. Autoreactive T and B cells responding to myelin proteolipid protein in multiple sclerosis and controls. Eur. J. Immunol. $21: 1461-1468$

52. Zhang, Y., D. Burger, G. Saruhan, M. Jeannet, and A. J. Steck. 1993. The T-lymphocyte response against myelin-associated glycoprotein and myelin basic protein in patients. Neurology. 43:403-407.

53. Link, H., J.-B. Sun, Z. Wang, Z. Xu, A. Love, S. Fredrikson, and T. Olsson. 1992. Virus-reactive and autoreactive $T$ cells are accumulated in cerebrospinal fluid in multiple sclerosis. J. Neuroimmunol. 38:63-74.

54. Perry, L. L., E. Bargaza-Gilbert, and J. L. Trotter. 1991. T cell sensitization to proteolipid protein in myelin basic protein-induced relapsing experimental allergic encephalomyelitis. J. Neuroimmunol. 33:7-15.

55. Kerlero de Rosbo, N., and C. C. A. Bernard. 1991. Degradation of myelin basic protein in human myelin is stimulated by autoantibodies: a new pathway for demyelination in multiple sclerosis? Satellite Symposium on Demyelination, Mechanism and Background, XIth International Congress of Neuropathology, Otsu City. T. Yonezawa, editor. 4-12.

56. Lebar, R., C. Lubetzki, C. Vincent, P. Lombrail, and J.-M. Boutry. 1986. The M2 autoantigen of central nervous system myelin, a glycoprotein present in oligodendrocyte membrane. Clin. Exp. Immunol. 66:423-443.

57. Lebar, R. 1987. Demyelination and autoimmunity. Pathol. Biol. 35:275283.

58. Gardinier, M. V., P. Amiguet, C. Linington, and J.-M. Matthieu. 1992. Myelin/oligodendrocyte glycoprotein is a unique member of the immunoglobulin superfamily. J. Neurosci. Res. 33:177-187.

59. Sun, J., H. Link, T. Olsson, B.-G. Xiao, G. Andersson, H.-P. Ekre, C. Linington, and P. Diener. 1991. T and B cell responses to myelin-oligodendrocyte glycoprotein in multiple sclerosis. J. Immunol. 146:1490-1495.

60. Trifilieff, E., B. Luu, G. Roussel, A. Espinosa de los Monteros, J. M. Sabatier, and J. Van Rietschoten. 1986. A specific immunological probe for the major myelin proteolipid. Confirmation of a deletion in DM-20. FEBS (Fed. Eur. Biochem. Soc.) Lett. 198:235-239.

61. Macklin, W. B., M. B. Lees, and E. Oberfield. 1984. Electroblot analysis of rat myelin proteolipid protein and basic protein during development. Dev. Neurosci. 6:161-168. 